\title{
UMA DÉCADA DO DECRETO № 5.154/2004 E DO PROEJA: BALANÇO E PERSPECTIVAS
}

$\begin{gathered}\text { G. FRIGOTTO* } \\ \text { Universidade do Estado do Rio de Janeiro } \\ \text { gfrigotto@globo.com }\end{gathered}$
Artigo submetido em agosto/2016 e aceito em setembro/2016
DOI: $10.15628 /$ holos.2016.4984

\section{RESUMO}

Este artigo tem como propósito refletir sobre o percurso da década de vigência do Decreto no 5.154/2004, no plano macroeconômico, político e social. Assim, discorremos sobre os seguintes aspectos: Contexto social e político das forças em disputa na sociedade e na educação da gênese do Decreto no 5.154/2004 e do
PROEJA, Decretos no 5.478/2005 e Decreto no $5.840 / 2006$ e as resistências de diferentes registros contra o ensino médio integrado e ao PROEJA e a confluência que busca seu desmanche por dentro numa direção oposta à sua gênese; e, por fim, que perspectivas se apresentam para tentar renascer das cinzas.

PALAVRAS-CHAVE: Decreto no 5.154/2004, Proeja, Contexto social e político.

\section{A DECADE OF DECREE N. 5.154/2004 AND PROEJA: BALANCE AND PERSPECTIVES}

\section{ABSTRACT}

This articles aims at thinking on the decade in which the Decree 5.154/2004 was valid. The discussions highlight the macroeconomic, political and social plan. Thus, we verse about the following aspects: social and political context of the forces under dispute in society and education; also, the creation of the Decree 5.154/2004 and the PROEJA, Decree 5.478/2005 and Decree
5.840/2006 and the oppositions from different occurrences against Vocational and Integrated High School Education and PROEJA and the convergence that seeks their dismantling from inside onto a direction contrary to their creation; finally, the perspectives presented in order to rise from the ashes.

KEYWORDS: Decreto no 5.154/2004, Proeja, Contexto social e político. 


\section{INTRODUÇÃO}

Efetivar um balanço de qualquer atividade humana, particularmente em sociedades cindidas em classes sociais com interesses antagônicos, implica o exercício de compreender as forças em disputa, as alianças, os conflitos, os antagonismos e as contradições nela presentes. Mais complexo se torna este balanço dentro de uma sociedade de capitalismo dependente ${ }^{1}$ como a do Brasil, cuja classe burguesa nunca teve um projeto de nação e sempre manteve e mantém os privilégios e seus interesses mediante ditaduras e golpes institucionais

A conjuntura dentro da qual se realiza o III Colóquio a Produção do Conhecimento em Educação Profissional nos interpela a decifrar a esfinge que nos rodeia cujas múltiplas faces concorrem para construir um novo golpe, não mais militar, mas pelas forças econômicas, políticas e jurídicas que constituem a classe burguesa brasileira historicamente associada aos centros hegemônicos do capital mundial.

Desde o resultado das últimas eleições presidenciais e já no processo das campanhas eleitorais os setores explicitamente de direita da classe dominante brasileira, mas não só, arquitetam, por diferentes mecanismos, mais um golpe com as teses de impeachment da Presidenta da república. Golpe didaticamente construído mediante a forma como a grande mídia empresarial, máquina de moer cérebros e poderoso aparelho de hegemonia dos grupos nacionais associados ao grande capital mundial, para liquidar o pouco do patrimônio nacional que nos resta, onde a Petrobrás é o ícone e, por isso, a sua privatização é a grande meta destes grupos.

Mas a sedimentação da hegemonia se dá, também, por outro aparelho de hegemonia, a escola mediante as concepções de conhecimento, métodos de ensino, avaliação e valores que dissemina. Ela é parte, portanto, da luta de classe nos conteúdos, nos métodos e na forma de educar. As disputas do capítulo sobre e educação no processo constituinte, a longa luta de negociação da Lei de Diretrizes e Bases da Educação Nacional e dos Planos Nacionais de Educação, bem como sua normatização em diferentes esferas são elementos irretocáveis para perceber como o braço político e jurídico da classe dominante brasileira age na negação do direito social e subjetivo da educação de qualidade à maioria das crianças e jovens brasileiros em pleno século XXI

Olhando o percurso da década de vigência do Decreto no 5.154/2004 e do PROEJA (Programa Nacional de Integração da Educação Profissional com a Educação Básica na Modalidade de Educação de Jovens e Adultos), no plano macroeconômico, político e social, a que somos interpelados a analisar neste III Colóquio, poderíamos perguntar: mas o que quer mais a classe burguesa brasileira e seus sócios do grande capital, mormente financeiro, além das concessões de não efetivar nenhuma mudança estrutural, mantendo ao seu critério o controle da moeda e fartando-se com juros inimagináveis em qualquer democracia mais sólida, mesmo nos termos

\footnotetext{
${ }^{1}$.O conceito de capitalismo dependente demarca a especificidade de sociedades capitalistas como o Brasil em que sua classe burguesa não busca construir uma nação autônoma, mas associa-se aos grupos hegemônicos do capital mundial num processo interno e externo de expropriação das riquezas e superexploração da classe trabalhadora. Resulta desta imbricação uma sociedade que concentra propriedade e riqueza na mão de minorias e ampliação da pobreza e miséria com a negação dos direitos fundamentais à vida. Um conceito que mostra que o foco da análise não é o conflito entre nações e povos, mas com a classe burguesa interna e externa. Para aprofundar esta questão indicamos de Florestan Fernandes as obras: Capitalismo Dependente e Classes sociais na América Latina (1972); A revolução Burguesa no Brasil. Ensaios de Interpretação Sociológica. (1974)
} 
restritos sob o sistema capitalista? Seriam as pequenas conquistas das frações mais pobres da classe trabalhadora mediante políticas e programas de uma parcela mínima de transferência de renda que tanto incomodam essa classe dominante?

O balanço dos dez anos depois do Decreto no 5.154/2004 que trata do ensino médio integrado e do PROEJA pode, ao mesmo tempo, nos dar pistas para responder estas questões e o que está subjacente e entender onde se situa a fraqueza de nossas lutas no âmbito amplo da frágil democracia brasileira sob ameaça. Com efeito, os embates que culminaram no Decreto no 5.154/2004 e o PROEJA explicitavam um contraponto do que havia sido, na década de 1990 sob o comando do Governo Fernando Henrique Cardoso e seu Ministro Paulo Renato de Souza, a política educacional orientada pelos critérios mercantis, em particular a educação básicas dos jovens e adultos.

Ao longo desta década há um volume significativo de análises em artigos, livros, capitulo de livros, teses, dissertações e monografias que tratam dos desdobramentos concretos tanto do Decreto quanto do PROEJA. Não é possível neste texto contemplar no detalhe esta produção, atenho-me, por isso, nos seguintes aspectos: Contexto social e político das forças em disputa na sociedade e na educação da gênese do Decreto no 5.154/2004 e do PROEJA, Decretos no $5.478 / 2005$ e Decreto № 5.840/2006 e as resistências de diferentes registros contra o ensino médio integrado e ao PROEJA e a confluência que busca seu desmanche por dentro numa direção oposta à sua gênese; e, por fim, que perspectivas se apresentam para tentar renascer das cinzas².

\section{CONTEXTO SOCIAL E POLÍTICO DAS FORÇAS EM DISPUTA NA SOCIEDADE E NA EDUCAÇÃO QUE ANTECEDEM O DECRETO № 5.154/2004.}

Das análises de Antônio Gramsci, sobretudo, retiramos a lição de que uma adequada análise dialética sobre o campo social implica uma adequada relação entre o conjuntural (análise do tempo presente) e o estrutural (o que define de forma mais orgânica historicamente a sociedade a que nos referimos. Pensamento social crítico, com matizes diferentes, entre outros nomes, Caio Prado, Celso Furtado, Nelson Wernek Sodré. Astrojildo Pereira, Florestan Fernandes, Otávio Ianni, Milton Santos, Carlos Nelson Coutinho, Francisco de Oliveira - nos permitem uma síntese de onde viemos, como nos constituímos e em que situação nos encontramos como sociedade.

A síntese mais aguda nos é dada pelos intelectuais que, a partir do método materialista histórico dialético, apreendem nossa especificidade de sociedade capitalista da periferia dos centros hegemônicos do capital e construída por um longo processo de colonização e que manteve por quase quatrocentos anos a escravidão. Essas análises nos permitem destacar três características ou determinações básicas deste processo constitutivo.

\footnotetext{
2. Neste balanço não busco a originalidade e sim a síntese de análises por mim já realizadas sobre o tema ou em conjunto com as colegas professoras Maria Ciavatta e Marise Ramos. Esta delimitação funda-se no fato de que com estas colegas participamos diretamente dos debates da proposta do Decreto no 5.154/2004 sendo que Marise Ramos era Diretora do Ensino Médio no Ministério da Educação. Com estas colegas e artigos de outros pesquisadores também participantes daqueles debates, elaboramos a primeira coletânea que buscou situar, como o próprio título revela, a concepção e as contradições do ensino médio integrado a que se refere o Decreto no 5.154/2004. Por esta razão, em parte, este texto tem, também, caráter de depoimento.
} 
A primeira e mais geral nos indica que a classe burguesa que se constitui no Brasil nunca buscou constituir efetivamente uma nação autônoma e soberana. Pelo contrário, sempre foi e continua sendo entreguista e, para tanto, associada aos grandes grupos econômicos dos centros hegemônicos do capital. Um dos momentos mais emblemático, depois de proclamada a República, de venda do patrimônio nacional foi o período das privatizações na década de 1990 sob o governo Fernando Henrique Cardoso. No atual momento, a forma como a grande imprensa empresarial trata da questão da corrupção na Petrobrás tem como interesse subjacente a sua privatização.

Portanto não se efetivou aqui o processo das revoluções burguesas clássicas em cujo projeto deram-se as formas estruturais (agrária, tributária, jurídica e política) bem como, os direitos à universalização do direito à saúde e à educação pública. Pelo contrário, há por parte da classe burguesa brasileira, por seu braço político, jurídico e burocrático uma resistência ativa e permanente às reformas estruturais e um sistemático protelar as medidas efetivas de garantia do direito universal à educação básica pública, assim como o direito à saúde pública.

A segunda característica, decorrente da primeira, define nossa especificidade como sociedade de capitalismo dependente de desenvolvimento desigual e combinado. Vale dizer, alta concentração da propriedade, do capital e da renda na mão de uma minoria cada vez mais rica, uma classe média minúscula e asfixiada e a maior da população mantida na pobreza e miséria. Mais da metade da terra está na mão de $1 \%$ de grandes latifúndios, em boa parte, atualmente propriedade de grupos nacionais e internacionais associados. Um sistema tributário dos mais injustos do mudo mantendo-se ao longo da história regressivo. As grandes fortunas, os bancos e financeiras pagam menos imposto que os assalariados. Um sistema jurídico quase que exclusivamente defensor da propriedade privada e do capital. No campo da educação convivemos com 13 milhões de analfabetos absolutos e metade dos jovens que não frequenta o ensino médio.

Diante deste sucinto quadro de injustiça, os intelectuais desta burguesia brasileira têm defendido a tese de que o Brasil não se alçou a país desenvolvido por culpa de que a maior parte da população não tem valores modernos. O economista Edmar Bacha, um destes intelectuais, utilizou a metaforicamente expressão belindia ${ }^{3}$ para expressar que o Brasil é uma composição de uma pequena Bélgica, moderna, com elevados níveis de escolaridade, integrada no mercado formal de trabalho e com perfil de alto consumo e de uma Índia, atrasada, pouco escolarizada, na informalidade, apegada a valores tradicionais e com baixo consumo. De forma cínica, a conclusão é que quem impede o Brasil avançar é a imensidão que pertence à Índia.

Numa direção diametralmente contrária as análises especialmente de Florestan Fernandes e Francisco de Oliveira mostram que no Brasil há uma relação orgânica entre o "atraso" e o "moderno". Para Oliveira, a imbricação do atraso, do tradicional e do arcaico com o moderno e desenvolvido potencializam nossa forma específica de sociedade de capitalismo dependente e de nossa inserção subalterna na divisão internacional do trabalho. Mais incisivamente, os setores denominados de atrasados, improdutivos e informais se constituem na condição essencial para a sustentação do núcleo interno integrado ao capitalismo orgânico mundial, tanto no plano econômico quanto o político.

No livro a Crítica Razão Dualista (19172) e sua atualização com o texto "o ornitorrinco" Oliveira (2003) metaforicamente compara o processo de desenvolvimento construído pela

3 . Expressão cunhada por Bacha em 1974 e retomada por livro. Ver: Edmar Bacha, 2012. 
burguesia brasileira, não como uma belindia, mas como um monstrengo social onde o analfabetismo, a precária educação básica, o trabalho informal e as mais radicais formas de precarização e flexibilização do trabalho, não são, ao longo de nossa história, como o pensamento dominante insiste, o entrave para o desenvolvimento, mas a forma específica de sociedade que se forjou. Uma sociedade que produz a desigualdade e se alimenta dela.

Oliveira mostra-nos que dentro desta forma societária específica a vigência do modo de regulação fordista, tanto no plano tecnológico quanto no plano social, foi parcial e precária e, do mesmo modo, nos situamos de forma ainda mais parcial e precária na mudança científica e técnica de natureza digital-molecular. Como assinala este autor, se a cópia já era problemática na base técnica fordista, cuja duração de utilidade era maior, agora a cópia multiplica seus custos sociais já que a velocidade das mudanças e muitíssimo maior. Não é contraditório, pois, que os nexos entre ciência, produção, trabalho e vida e as demandas de educação e de formação técnico-profissional tende ser, também, parciais e precários.

Por fim, nesta breve síntese do que define a nossa especificidade como sociedade, a forma mediante a qual a burguesia brasileira mantém e alimenta o monstrengo social que nos tronamos. Trata-se de uma classe burguesa que manteve esta forma societária com duas ditaduras, ainda que distintas, ao longo do século XX e de tempos em tempos efetiva golpes institucionais.

Após a ditadura Vargas a sociedade Brasileira viveu um período de intensa mobilização e criatividade no campo da cultura (cinema novo, música popular, teatro popular) e uma intensa mobilização pelas reformas de base. Este rico processo foi interrompido com um golpe civil-militar ou empresarial militar, com o apoio ostensivo da grande mídia e impôs uma ditadura por 20 anos.

Na década de 1980 a sociedade brasileira mobilizou-se intensamente na luta pela retomada da democratização após vinte anos de arbítrio ditatorial. O processo constituinte foi um marco importante e, na letra, a constituição promulgada em 1988 continha avanços significativos no plano dos direitos econômicos, sociais e educacionais, incluindo dispositivos de controle social na mídia empresarial.

A década de 1990, agora não mais sob os auspícios das forças armadas, cujo preço por afiançar os interesses desta burguesia, da qual parte delas a constituem, veio o desmanche gradativo dos avanços constitucionais mediante a ditadura do mercado e as privatizações sob a égide do credo neoliberal. No campo educacional protelou-se a proposta de Lei de Diretrizes e Bases da Educação Nacional construída no debate e negociação até figurá-la com um substitutivo à feição dos interesses dos senhores do mercado, mormente do educacional. O mesmo procedimento pautou a aprovação do atual Plano Nacional de Educação, que devia ser aprovado em 2010 e só o foi em 2014 depois de fortemente desfigurado da proposta original negociada com a sociedade.

Talvez as duas questões acima apresentadas sobre o que mais quer essa burguesia despótica, anti nacional e golpista além do que já usurpou tenham compreensão na definição que o Filósofo Leandro Konder, ao voltar do exílio em 1979, dá à direita brasileira.

O pluralismo da ideologia da direita pressupõe uma unidade substancial profunda, inabalável: todas as correntes conservadoras, religiosas ou leigas, otimistas ou pessimistas, metafísicas ou sociológicas, moralistas ou cínicas, científicas ou místicas concordam em um determinado ponto essencial. Isto é: em impedir que 
as massas populares se organizem, reivindiquem, façam política e criem uma verdadeira democracia (KONDER, 1979, p.1)

No que se refere ao plano estrutural acima brevemente traçado da sociedade Brasileira o ex líder operário Luiz Inácio Lula da Silve, ao ascender ao poder depois de três tentativas, nada estava alterado. O que a constituição assegurou na letra, em seguida, foi sendo alterado ou postergado na prática. Para exemplificar dois aspectos: imposto sobre grandes fortunas e controle social e econômico da mídia empresaria. Mais que isso, o ainda não empossado presidente Lula, assinou um documento - Carta aos brasileiros na qual, em última análise, prometia não alterar o fundamenta do tecido estrutural. E, por certo, a classe dominante não pode acusar o ex Presidente de ter feito alguma alteração significativa estruturalmente. Mas a imposição da classe dominante desta carta compromisso mirava certamente a desconfiança das teses históricas das forças sociais que elegeram Lula da Silva.

Com efeito, desde a primeira campanha de 1989, a base social dominante de apoio a Luiz Inácio Lula da Silva era composta, em termos das lideranças, das forças heterogêneas de esquerda que historicamente buscaram construir uma nação autônoma soberana e que para tanto demandava mudanças estruturais, ainda que dentro da ordem capitalista, mas contra esta mesma. Para parte destas forças, o horizonte a construir é a superação do capitalismo e a formação da sociedade socialista, cuja condição prévia, ainda que não suficiente, é o fim da propriedade dos meios e instrumentos de produção.

Como expõe Francisco de Oliveira, um dos intelectuais de análise mais aguda de nosso processo histórico e tendo vivido sua juventude sob a ditadura Vargas e sofrido a perseguição ao longo da ditadura civil militar de 1964, abria-se uma nova possibilidade de fundar a nação sob outras bases.

A breve citação abaixo deste intelectual nos dá os elementos políticos para entender porque o teor do Decreto no 5.154/2004 era o avanço possível naquele início de governo, mas que como foi concebido, ainda que não como foi finamente aprovado, se poderia avançar para a escola unitária politécnica/tecnológica, mas que isso dependeria de avanços nas mudanças estruturais de nossa sociedade.

Na periodização de logue duré brasileira, a eleição de Luiz Inácio Lula da Silva para a Presidência da República, ancorada na excepcional performance do Partido dos Trabalhadores e de uma ampla frente de esquerda, tem tudo para ser uma espécie de quarta refundação da história nacional, isto é, um marco de não retorno a partir do qual impõem-se novos desdobramentos. [...]. É tarefa das classes dominadas civilizar a dominação, o que as elites brasileiras foram incapazes de fazer. $O$ que se exige do novo governo é de uma radicalidade que está muito além de simplesmente fazer um governo desenvolvimentista (OLIVEIRA, 2003, p.3).

Os desdobramentos a que se refere implicariam confrontar os interesses da classe burguesa brasileira e seu histórico projeto de sociedade de desenvolvimento desigual e combinado. Como veremos logo adiante, já em 2004, Oliveira mostra que estes interesses não estavam sendo confrontados e o caminho do não retorno não ocorrera. É dentro deste quadro que nasce o ensino médio integrado e seu percurso tortuoso e indefinido até o presente. 


\section{A GÊNESE HIBRIDA DO DECRETO N5.154/2004 SUAS (IM)POSSIBILIDADES E SEUS (DES)CAMINHOS.}

Apoiados em Marx e em Gramsci pode-se afirmar que LuizInácio Lula da Silva iniciou seu governo em condições objetivas marcadas pela herança de uma realidade econômica, social, política, jurídica e educacional rebelde. De fato, nos oito anos do governo Fernando Henrique Cardoso realizou, de forma célere, a contra-reforma daquilo que a Constituição recém aprovada apontava mediante as políticas neoliberais na economia com a venda do patrimônio nacional pelas privatizações e, na educação, mediante a concepção mercantil em todos os níveis, mormente o ensino médio pelo Decreto 2.208/1997 e pela abertura total da privatização no ensino superior.

O ministro Paulo Renato de Souza, não por acaso, ficou os oito anos como ministro. Como intelectual qualificado e larga experiência nos organismos internacionais, mormente o Banco Mundial, devotou-se em implementar as orientações destes organismos. Orientações em sentido diametralmente oposto às lutas pela escola unitária e da concepção politécnica de educação. Desde aquele momento, e de forma crescente ao longo das últimas décadas a orientação do Banco Mundial, Organização do Comércio, encampada pela UNESCO (Organização das Nações Unidas para a educação, a ciência e a cultura), tem sido, além de oferecer uma gama diferenciada de níveis e natureza de escolaridade efetivar uma clara destinação entre a formação acadêmica geral da formação técnico-profissional. O Decreto no 2.208/1997 é expressão clara desta orientação. Orientação defendida, desde a década de 1970, pelo economista Cláudio de Moura Castro, um quadro altamente qualificado e que teve acento nestes organismos como promotor desta perspectiva dual e de diferenciações dentro da dualidade.

Em 1985, eu participava de uma comissão do MEC para examinar essas escolas ${ }^{4}$. Sugeri que fosse separada a vertente acadêmica da profissional Assim, quem quisesse fazer vestibular não perderia tempo nas oficinas, deixando as vagas para quem pretendesse exercer as profissões aprendidas. Palavras ao vento. Em meados de 1990, estava no Banco Interamericano de Desenvolvimento (BID) e assessorava o ministro Paulo Renato, interessado em um empréstimo para o ensino técnico. Mas a proposta esbarrava no elitismo e na distorção dos cursos. Diante do impasse, desenterrei a minha proposta que foi aceita e implementada. Quem quisesse o vestibular escolheria o ramo acadêmico. Quem quisesse a profissão iria para o ramo técnico, depois de formado no ensino médio. Ou, então, poderia fazer o médio, simultaneamente. (CASTRO, 2012, p. 3).

Imaginar que as forças sociais e políticas ligadas ao projeto até então dominante de sociedade e de educação e a sua doutrinação nas instituições ficassem passivas a qualquer mudança que atentasse aos seus interesses, seria uma debilidade teórica e uma enorme ingenuidade política. Do mesmo modo, imaginar que se poderia alterar a LDB ou um decreto impositivo, seria não distinguir o poder da classe dominante em todas as esferas da sociedade e o desafio de um novo governo com a base social ligada historicamente à classe trabalhadora.

O grupo de pesquisadores que opinou na sugestão de nomes para ocupar tarefas da gestão no ensino médio, desde os primeiros momentos, foi convocado a participar dos debates não apenas no plano teórico, mas na disputa e formulação política para fazer valer concepções de

\footnotetext{
${ }^{4}$. Referência à antiga rede de escolas Técnicas Federais, hoje em sua maioria Institutos Federais de Educação, Ciência e Tecnologia
} 
educação básica na ótica dos interesses da classe trabalhadora. De imediato percebeu-se que entre a formulação teórica e a luta política situava-se a correlação de força na disputa dos interesses das classes e frações de classes presentes em diferentes âmbitos da sociedade.

O texto - Ensino Médio integrado e sua relação com a educação profissional: explicitando discordância, aproximações e sugestões - (FRIGOTTO e CIVATTA, 2003) contém as indicações básicas destes embates acerca da natureza da nova concepção da educação profissional integrada à educação básica. Documento este, precedido por uma consulta às instituições da sociedade civil que revela um contraponto ao método impositivo e pelo alto do Decreto no 2.208/1997.

No 'Documento à Sociedade ${ }^{5}$ ' salientou-se que o mesmo foi marcado pela consulta e pelo diálogo com a sociedade civil e política como estratégia de reconhecimento de diferentes interesses, bem como pela transparência nas discussões e nas decisões. Um processo que tem como pressuposto que o exercício da democracia implica uma relação educativa entre o Estado e a sociedade. Destacou-se, de outra parte, que o novo decreto se impunha dentro das circunstâncias dadas e do tempo da decisão política. Ao mesmo tempo, ao demarcar outra direção na concepção, no conteúdo e nas práticas do Ensino Médio e em sua articulação com a Educação Profissional, este instrumento explicita uma contradição entre o instrumento almejado e a decisão possível. (FRIGOTTO e CIAVATTA, 2003, p. 1)

Neste documento expusemos uma síntese das três posições que precederam à decisão final sobre o Decreto $\mathrm{n}$ - 5.154/2004 e que assim se definiam: as posições; e justificativas pela simples revogação do Decreto no 2.208/1997 e o retorno à LDB (Lei no 9.394/1996; as posições e justificativas pela não revogação do Decreto no. 2.208/1997 e as posições e justificativas pela revogação do Decreto no 2.208/1997 e sua substituição por um novo decreto. A decisão de seguir a terceira opção não foi decorrência de uma posição deliberada reformista como sustentam algumas teses abstratas apoiadas numa postura moral do dever, mas da correlação de forças na sociedade e no governo. Um governo, isto sim, que em seguida não sustentou sequer o teor do Decreto no 5.154/2004 já depurado de sua proposta original.

O documento supracitado sinaliza que do processo inicial de consulta à sociedade realizado em fevereiro de 2003 passou-se mais de um ano. Neste período ampliaram-se as consultas e foram realizados dois seminários - um primeiro sobre o ensino médio e o segundo sobre educação profissional. O seminário sobre ensino médio foi fundamental para demarcar sua concepção centrada no conhecimento, trabalho e cultura, bases da educação integral, politécnica e na construção da escola unitária. Um dos aspectos que mereceu centralidade foi em relação aos sujeitos do ensino médio, considerando-se não somente a profunda desigualdade entre as classes e grupos sociais, mas também as particularidades regionais. A coletânea (FRIGOTTO e CIVATTA, 2004) condensa as análises produzidas neste seminário.

Se o seminário sobre ensino médio não despertou nenhum interesse das instituições ligadas ao mundo da produção e dos negócios, o que tratou da educação profissional e técnica foi intenso. O Sistema S, especialmente o SENAI (Serviço Nacional de Aprendizagem Industrial), lotou hotéis e participou massivamente na disputa da concepção, organização e financiamento da

\footnotetext{
5 . Referência à consulta feita em fevereiro de 2003 a diversas instituições da sociedade civil sobre a proposta do novo Decreto a ser promulgado.
} 
educação profissional e técnica. Ao não querer a integração, mas a articulação da educação profissional e técnica à educação básica e não abrir mão da organização e gestão privada do fundo público que recebe explicitava-se que a classe burguesa brasileira não estava disposta a permitir alterações significativas para a formação técnica e ideológica da classe trabalhadora.

O dado mais claro do poder da classe burguesa, através de seus representantes nos institutos classistas, no parlamento e no judiciário revelou-se no mesmo dia da sessão final do seminário de educação profissional onde se votou as conclusões e recomendações. Se no debate, no que concerne às conclusões sobre a orientação da educação profissional e técnica, as teses defendidas pelos educadores vinculados à luta da classe trabalhadora foram vitoriosas, os deputados e senadores conservadores ligados à base do governo imediatamente proclamaram que se isso fosse para valer ele não teria maioria em suas matérias. E quais eram as conclusões e recomendações: integração da formação profissional e técnica à educação básica e não articulação como defendiam os representantes dos empresários; recursos públicos exclusivamente a educação pública e gestão democrática, incluindo-se um controle sobre o Sistema S.

Entre a intencionalidade do teor do Decreto no 5.154/2004 e sua aprovação pode-se destacar quatro determinações correlacionadas que lhe deram um caráter hibrido e apenas indicativo e não compulsório, até mesmo onde poderia ser que é o caso da Rede Federal. Nesta rede o termo foi preferencialmente integrado.

Um primeiro e mais geral não foi apenas o leque de forças heterogêneo que amarrou o governo, se não também a opção que foi definindo de conciliação com as forças do capital. Se por um lado não se poderia esperar do governo Luiz Inácio Lula da Silva uma revolução socialista, por outro, tampouco se esperava o abandono das demandas da base social que o elegeu ligadas a direitos historicamente negados.

O segundo foi a pressão dos institutos privados ligados à indústria, comércio e agronegócio e seus intelectuais atuantes dentro ou fora do aparelho do Estado, sempre com apoio incondicional da grande mídia empresarial. Isto fica claro pelo que expõe Cláudio de Moura Castro:

Após a mudança de governo, entraram no MEC os inconformados com a separação ${ }^{6}$. Tentaram voltar atrás, mas, em virtude da grita, somente as escolas federais tornaram a integrar o acadêmico ao técnico. As razões para juntá-los permanecem misteriosas para a cabeça simplória deste autor. A bandeira desfraldada era uma tal "politecnia", criada por Gramsci, lá pelos anos 1920, enquanto morava na cadeia. Prescrevia um ensino combinando as disciplinas técnicas com as acadêmicas e com o trabalho. Mais que isso, não entendi. (ibid)

A terceira determinação relaciona-se ao fato de que o ensino médio dentro do regime federativo dá aos estados a atribuição do ensino médio e autonomia na sua definição. $O$ fato do Decreto no 5.154/2004 não obrigar o Integrado dependia dos estados aderirem ou não. Apenas três estados aderiram em 2005 - Paraná, Espírito Santo e Santa Catarina, sendo que já nos primeiros seis meses como os governos do Espírito Santo e de Santa Catarina saíram da aliança com o governo Federal e interromperam o trabalho de implantação.

Uma última determinação, mas não menos decisiva, foi o pouco apoio na defesa do integrado no campo crítico, quer pelo fato da discordância com o referido Decreto, quer por uma

\footnotetext{
${ }^{6}$ Aqui está se referindo ao Decreto no 2.208/1997
} 
crescente desmobilização em face aos rumos que o governo tomava no campo da educação e em outras áreas. Um processo que Oliveira (2009 e 2012) denominou de hegemonia às avessas para designar que ao invés de ampliar a politização da base que o elegera, a despolitizou. Com isto, gerou-se um duplo enfraquecimento da esquerda. Por um lado, um processo de transformismo de quadros que eram da esquerda e, por outro, a fragmentação - com novos partidos e centrais sindicais.

O percurso dos dez anos, pelas razões acima expostas nos coloca diante de uma esfinge a decifrar que tem duas faces que se potenciam e que, mesmo de sinais opostos, podem levar para um desfecho de retrocesso com as forças sociais que impuseram o Decreto $n=2.208 / 1997$. Por um lado se expressa não apenas pela concentração descomunal de riqueza e de renda pela classe burguesa brasileira, mormente na sua fração financista, e que toma de assalto o fundo público, mas por uma investida orgânica e aparelhada como nunca pela mídia empresarial, de vingança e ódio aos pobres e do pensamento social crítico. Por outro, a face da esfinge se apresenta por um campo de esquerda estraçalhado pela hegemonia às avessas e pela dificuldade histórica, mesmo no dissenso, de encontrar consensos básicos na luta contra o que Florestan Fernandes (1980, p. 145) definiu, referindo-se à classe burguesa brasileira, de minoria prepotente e seus interesses.

A situação presente é, pois, mais grave do que o contexto da ditadura civil militar dos anos 1964 até o início da década de 1990. A classe burguesa brasileira e seus vínculos com as burguesias dos centros hegemônicos do capital, já não precisam diretamente da mão armada, tem a arma da grande mídia para tornar interesses de minorias como se fossem da grande maioria

Se Gramsci vivo estivesse, certamente, à luz de suas análises nos diria: como nunca os grupos privados da sociedade civil tomaram por dentro o Estado brasileiro para preservar seus interesses particulares de acumulação de capital. Um assalto legalizado, mas injusto, ao fundo público. E como nunca tomaram por dentro o Estado para implementar formulação das concepções mercantis da educação que lhes convém. Presenciamos um avanço sem precedentes, de bancos, redes privadas de comunicação, institutos privados vinculados a grandes empresas reunidas em torno do nome cínico de Todos pela Educação.

Quem são estes protagonistas? O núcleo orgânico é constituído por fundações e institutos PRIVADOS, entre outros: Fundação Lemann, Fundação Roberto Marinho, Fundação SM, Fundação Itaú Social, Fundação Telefônica Vivo, Fundação Victor Civita, Instituto Gerdau, Instituto Natura, Instituto Razão Social, Itaú BBA Associação Brasileira do Agronegócio (ABAG), Instituto Airton Senna. O que é mais perverso é de que seus objetivos são veiculados por dentro do Ministério da Educação, Conselho Federal de Educação, Conselhos Estaduais e Secretarias estaduais e municipais de Educação e apoiados pelo COINSED (Conselho Nacional de Secretários de Educação) e UNIDIME (União Nacional dos Dirigentes da Educação)

Em síntese, o que em 1977 o slogan do SENAI, como assinalei na dissertação de mestrado acima referida, era ensinar o que serve aos industriais. Hoje este lema amplia-se e consolida-se e para a educação em geral: a educação que serve ao mercado ao capital. O ensino médio integrado já não ameaça.

A segunda, que potencia a primeira, é que não há forças em movimento na perspectiva da escola unitária e da educação politécnica, salvo na agenda e na luta concreta de parte das escolas dos assentamentos do MST e de algumas experiências. A passividade diante da meritocracia e do 
produtivismo, que dela decorre e a o alimenta, é um sintoma de quebra da solidariedade coletiva no campo da esquerda, elo fundamental em qualquer luta contra-hegemônica.

Soma-se a isto, neste particular, boa parte da produção acadêmica que se faz nas universidades e que se alimenta de longos debates abstratos, mas sem nenhum vínculo imediato ou mediato com as lutas e com as ações que buscam, de dentro de velhas e opacas estruturas sociais e educacionais, construir mudanças que alteram estas estruturas na perspectiva de sua superação. Trata-se de análises, mesmo quando bem intencionadas, que acabam escorregando para julgamentos morais, ou posturas dogmáticas e, não raro, por julgamentos apressados do que seja revolucionário ou reformista. O que fica ausente nestas análises é o caráter contraditório de toda a realidade histórica. Nenhuma mudança histórica começa pelo novo, mas pela dialética de superação das velhas estruturas e relações sociais.

O que tramita no Congresso Nacional, com apoio do MEC e sob a direção do Todos pela Educação, é uma proposta de reforma do ensino médio que retroage às leis da equivalência da primeira metade do Século XX. Isto indica que na realidade brasileira o ensino médio integrado, na perspectiva da educação omnilateral e politécnica é algo inaceitável à classe burguesa brasileira e seus intelectuais. Caso retornem ao poder as forças sociais que venderam o país e impuseram o Decreto no 2.208/1997, a travessia poderá ser para o retrocesso.

\section{INDICAÇÕES SOBRE O ENSINO MÉDIO INTEGRADO EXISTENTE NOS ESTADOS E NA REDE FEDERAL: O EMBATE NÃO FOI EM VÃO.}

A questão que nos interpela e engendra indicações que nem tudo está perdido relacionase ao fato de que apesar do governo, já em 2005, ter jogado o Decreto no 5.154/2004 à margem e ao seu destino (FRIGOTTO, CIAVATTA e RAMOS, 2005b); a gritaria dos opositores frontais ter aumentado; e, e alguns críticos acadêmicos do campo de esquerda terem mantido sua posição contra, o ensino médio integrado não só não morreu como tende a crescer.

Com base em duas pesquisas que coordeno e fase final ${ }^{7}$, de um balanço de dissertações e teses que tratam do ensino médio integrado podemos vislumbrar, ainda que de forma muito diversa nos estados e na Rede Federal de Educação Profissional e Tecnológica, quem o sustenta é a persistência dos que fazem uma relação inseparável entre a crítica e a ação nas circunstâncias dadas pela realidade. Neste sentido, Marx em exposição no Conselho Geral da AIT em agosto de 1869 anuncia que indubitavelmente, por um lado, é necessário modificar as condições sociais para criar um novo sistema de ensino, por outro; falta um sistema de ensino novo para poder modificar as condições sociais. Consequentemente é necessário partir da situação atual (MARX e ENGELS, 2011, p. 138

No processo de embates na construção da proposta do Decreto no 5.154/2004 foi feita uma consulta a instituições científicas, sindicais e privadas e a tipologia a que se chegou é de que um pequeno número mantinha-se na defesa do Decreto n $2.208 / 1997$, também outra minoria

\footnotetext{
7 Refiro-me aos projetos: Os Institutos Federais de Educação, Ciência e Tecnologia e sua relação com o ensino médio integrado e o projeto societário e de desenvolvimento (2003-2010), apoiado pelo CNPq e cuja conclusão será em fevereiro de 2016 e o projeto Ofertas Formativas e características Regionais: A educação Básica de Nível Médio no Estado do Rio de Janeiro, concluído em agosto de 2015 com o apoio da FAPERJ.
} 
mostrava-se favorável a novo Decreto e a grande maioria mostrava-se indiferente. Alguns dados mostram que apesar de tudo a indiferença diminui, ainda que esteja longe do desejável.

Dados de diferentes fontes de pesquisa assinalam nesta direção. A participação de eventos na rede federal de ensino indica que a percepção da relevância de buscar-se avançar na perspectiva do ensino médio integrado vem ganhando mais espaço. As duas tabelas a seguir nos dão dados que apontam neste sentido.

Tabela 1. Percentual de oferta da Educação Profissional Integrada ao Ensino Médio (EMI) em relação à oferta total de Educação Profissional (EP)

\begin{tabular}{|c|c|c|c|}
\hline Ano & EP & EMI & EMI/EP x 100 \\
\hline 2011 & 993.187 & 257.713 & 25,9 \\
\hline 2012 & 1.063 .655 & 298.545 & 28 \\
\hline 2013 & 1.102 .661 & 338.390 & 30,7 \\
\hline
\end{tabular}

Fonte: BRASIL. INEP. Sinopse estatística da educação básica. Disponível em http://portal.inep.gov.br/básica-censoescolar-sinopse-sinopse>. Consulta em 14/07/2014 Tabela produzida pela profa. Drä Marise Ramos

Os dados da tabela 1 indicam que em relação à oferta geral da educação profissional integrada, de 2011 a 2013 passou-se de 25,9\% para 30,7\%. Um crescimento relativamente pequeno, mas que indica um processo crescente de adesão.

Tabela 2: Número de Matrículas da Educação Profissional Integrada ao Ensino Médio por Dependência Administrativa (2011-2013).

\begin{tabular}{|c|c|c|c|}
\hline Ano & Total & Pública & Privada \\
\hline 2011 & 257.713 & $236.129(92 \%)$ & $21.584(8 \%)$ \\
\hline 2012 & 298.545 & $273.431(92 \%)$ & $25.114(8 \%)$ \\
\hline 2013 & 338.390 & $312.122(92 \%)$ & $26.268(8 \%)$ \\
\hline
\end{tabular}

Fonte: BRASIL. INEP. Sinopse estatística da educação básica. Disponível em http://portal.inep.gov.br/básica-censoescolar-sinopse-sinopse>. Consulta em 14/07/2014 Tabela produzida pela profa. Draii Marise Ramos

Pelos dados da Tabela 2 evidencia-se que a rede privada de ensino não aderiu, a não ser d e forma muito pequena, ao ensino médio integrado. Ao longo dos três anos, de forma inalterada, a rede pública é responsável por $92 \%$ do integrado e a rede privada penas $8 \%$. Trata-se, em especial nas escolas privadas que atendem a classe média, da afirmação da dualidade e um desprezo pela formação técnica.

Dados de uma pesquisa que acabamos de concluir sobre as Ofertas Formativas de Ensino Médio no estado do Rio de Janeiro FRIGOTTO, 2015, observou-se que na rede federal, de 2007 a 2012, houve um incremento de $22 \%$ na oferta da forma integrada. Tomando-se os dois Institutos Federais do estado do Rio de Janeiro, a indicação é bastante positiva. De 2009 a 2013 houve um acréscimo de aproximadamente cinco mil matrículas no Instituto Federal Fluminense (IFF) e a forma integrada, incluindo os seis cursos do PROEJA, era de $40 \%$ O Instituto Federal Rio de Janeiro (IFRJ) tem um número menor de cursos de nível médio, em compensação $70 \%$ se efetivam na forma integrada.

A grande dívida, em todos os âmbitos, é em relação ao PROEJA. Os estudos específicos que realizamos na pesquisa acima indicada sobre PROEJA apontam a tendência de um processo de deslocamento que pode significar a liquidação desta política. Com efeito, a criação do PRONATEC (Programa Nacional de Acesso ao Ensino Técnico e Emprego) sinaliza a redução da educação de jovens e adultos de direito à educação básica universal e unitária para formação aligeirada e restrita de preparar para o trabalho simples. 
Este deslocamento fica patente no fato de que o PROEJA nasceu sob a vigência do Decreto no 5.478/2005, mas no ano seguinte, após a revogação deste, passou a ser regulamentado pelo Decreto no 5.840/2006. Nesta mudança, o Programa deixou de ser exclusivamente oferecido por instituições federais de ensino, podendo ser ofertado pelas redes de ensino estadual, municipal e pelo setor privado através do "Sistema S".

Ao examinar a natureza de oferta da rede federal, tomando como referência da pesquisa o Colégio Pedro II e os Institutos Federais que atuam no estado do Rio de Janeiro e da FAETEC (Fundação de Apoio à Escola Técnica (acrônimo FAETEC) a conclusão geral é de que o PROEJA, que está próximo a completar uma década, carrega consigo a marca pesada da trajetória marginal da educação de jovens e adultos trabalhadores na história da educação brasileira. Apesar dos razoáveis índices de conclusão de curso no Colégio Pedro II e manutenção de significativo número de matrículas, ainda são muito alarmantes os índices de evasão escolar mesmo nesta instituição e, mais severamente, no IFRJ e FAETEC.

Dentro da realidade dos estados da federação onde, em média, mesmo atendendo a apenas $50 \%$ dos jovens em idade com o direito ao ensino médio e grande parte em descompasso com a idade/série, não se poderia esperar que o PROEJA assumisse alguma prioridade. Pelo contrário, os dados que colhemos nesta pesquisa revelam que no caso do Estado do Rio de Janeiro observa-se uma política de diminuição sensível de escolas que oferecem o PROEJA.

Esta realidade não é muito diversa no âmbito nacional e indica que a sociedade brasileira continua mantendo uma dupla negação ao direito social e subjetivo da educação básica. Primeiramente por não universalizar a educação básica de qualidade e, segundo, por não ter uma política efetiva enfrentar estatísticas que são chocantes. Com efeito, Chegamos na segunda década do século XXI, com 13 milhões de analfabetos absolutos e mais da metade dos jovens entre 15 e 24 anos fora da escola, sem concluir a última etapa do ensino médio. Um total de 62,2 milhões de jovens e adultos com mais de 15 anos não completaram o ensino fundamental, dos quais 29,3 milhões têm menos de quatro anos de estudo. Dentro destes números cresce o contingentes dos que são denominados de geração nem nem - Que não estudam e nem trabalham, mais de $19 \%$ de jovens entre 15 e 29 anos de acordo com a Pesquisa Nacional por Amostragem de Domicílio ( PENAD) de 2012. Isto representa 10 milhões de jovens que na realidade estão fazendo alguma coisa, grande parte junto ao trabalho ilegal ou ilícito.

\section{A TÍTULO DE CONSIDERAÇÕES FINAIS}

Do balanço das forças sociais em disputa nesta década de luta pelo ensino médio integrado nota-se que a forma específica de construção de nossa sociedade nos indica, de forma inequívoca, que as mudanças estruturais ainda que, como indicava Florestan Fernandes, inicialmente dentro da ordem burguesa, não virão da classe dominante brasileira e de seus representantes no âmbito político, jurídico, religioso e do monopólio da grande imprensa. Isto somente poderá mudar pela organização dos movimentos sociais, sindicatos e intelectuais, forças políticas e culturais que efetivamente lutam pelos direitos dos trabalhadores e forcem as mudanças estruturais que mantém uma sociedade, que, como sublinhamos na analisa Francisco de Oliveira, produz a miséria e se alimenta dela - uma sociedade desigualitária e sem remissão. 
Aos educadores que atuam no sistema público e os que vendem a sua força de trabalho na iniciativa privada cabe aprofundar a leitura crítica sobre as forças conservadoras que impedem o direito à educação básica e a submetem cada vez mais aos seus interesses privados. Concomitante a isto, um esforço de organização e de mobilização junto às forças que sempre lutaram em defesa do direito à educação pública, universal, gratuita, laica e unitária. Uma luta que implica o resgate do aluno como sujeito e do professor, igualmente sujeito.

Mas uma luta que tem que ser concomitante, no presente, por manter a ordem democrática ameaçada por mais um golpe institucional em curso. Sem esta manutenção, as reformas estruturais, condição necessária, para os avanços efetivos nos direitos sociais, dentre eles, o da educação pública básica universal não se efetivarão.

Por fim, a dificuldade de setores da esquerda de apoiarem a proposta do ensino médio integrado, tendo como base a ciência, a cultura e o trabalho, no horizonte da formação omnilateral e politécnica e como travessia para a superação da dualidade educacional, talvez indique a necessidade de autocrítica das posturas centradas no dever ser. A luta na construção do direito universal da educação escolar básica desinteressada (fundamental e média) e unitária, nas condições de uma sociedade profundamente desigual não pode pautar-se no dever ser, mas em conquistas que avancem nesta direção na sociedade e na educação. O que nos interpela historicamente com campo de esquerda e, no momento mais visceralmente, é busca, numa direção antagônica da direita, daquilo que em nosso pluralismo pressupõe uma unidade substancial profunda, inabalável. Trata-se de uma interpelação política e ética no plano estratégico da luta contra as fortalezas do capital e seus processos educativos alienadores.

\section{REFERÊNCIAS BIBLIOGRÁFICAS}

1. BACHA, Edmar. Belindia 2.o. Fabulas e ensaios sobre o país dos contrastes. Rio de Janeiro, Civilização Brasileira, 2012

2. CASTRO, Cláudio de Moura. O dilema do ensino técnico. São Paulo: Revista Veja. 15 de outubro de 2012.

3. FERNANDES, Florestan. Capitalismo dependente e classes sociais na América Latina. Rio de Janeiro, Editora Zahar, 1973.

4. FERNANDES, Florestan. A revolução burguesa no Brasil: ensaio de interpretação sociológica. Rio de Janeiro: Zahar, 1974.

5. FERNANDES, Florestan. A sociologia no Brasil. Petrópolis, Vozes, 1980.

6. FRIGOTTO, Gaudêncio. Efeitos cognitivos da escolaridade do SENAI e da escola acadêmica: existe uma escola para cada classe social? 1977. Dissertação. Instituto de Estudos Avançados em Educação (IESAE), Fundação Getulio Vargas, Rio de Janeiro, 1977.

7. FRIGOTTO, Gaudêncio (coordenador). Ofertas Formativas e características Regionais: A educação Básica de Nível Médio no Estado do Rio de Janeiro. UERJ/FAPERJ, Rio de Janeiro, 2015. Relatório de pesquisa.

8. FRIGOTTO, Gaudêncio e CIAVATTA, Maria. Ensino Médio Integrado em sua relação com a educação profissional: explicitando discordâncias, aproximações e sugestões. Brasília, 09.03.2003. Documento síntese. Mímeo.

9. FRIGOTTO, Gaudêncio e CIAVATTA, Maria. Ensino médio ciência, cultura e trabalho. (orgs) . MEC, Brasília, 2004

10. KONDER, Leandro. A unidade da direita. Jornal da República. São Paulo, 20/9/1979 
11. MARX, Karl, in: LEITE, Valter de Jesus. A relação trabalho e educação na construção da forma escolar dos complexos de estudo da escola itinerante do Paraná. Rio de Janeiro, FIOCRUZ, 2015. Monografia de curso de especialização.

12. OLIVEIRA, Francisco. de. A crítica à razão dualista - $\mathbf{O}$ ornitorrinco. São Paulo, Boitempo, 2003.

13. OLIVEIRA, Francisco. de. A economia Brasileira: A crítica da razão dualista. Petrópolis/RJ, Vozes, 1972

14. OLIVEIRA, Francisco de. 0 avesso do avesso. São Paulo, Revista Piauí, no 37, outubro 2009

15. OLIVEIRA, Francisco de. Revista reportagem, n. 41, fev.2003. Entrevista concedida a Fernando Haddad e Leda Paulani.

16. OLIVEIRA, Francisco de. Hegemonia às avessas . In; Oliveira, Francisco de, Braga, Ruy e Rizek, Sibele. Hegemonia às Avessas. São Paulo, Boitempo, 2010. p.21-29 